DOI: 10.11606/issn.2238-3867.v16i1 p214-234

sala preta

ppgac

\title{
NEMMOKNA - sobre chegadas, gestos e lembranças de outros lugares
}

\section{NEMMOKNA - about arrivals, gestures and memories of other places}

\section{Sayonara Pereira}

Sayonara Pereira

Doutora em Dança pela Universidade Estadual de Campinas (Unicamp), com pósdoutorado pela mesma instituição. Professora efetiva da Escola de Comunicação e Artes da Universidade de São Paulo (ECA-USP)

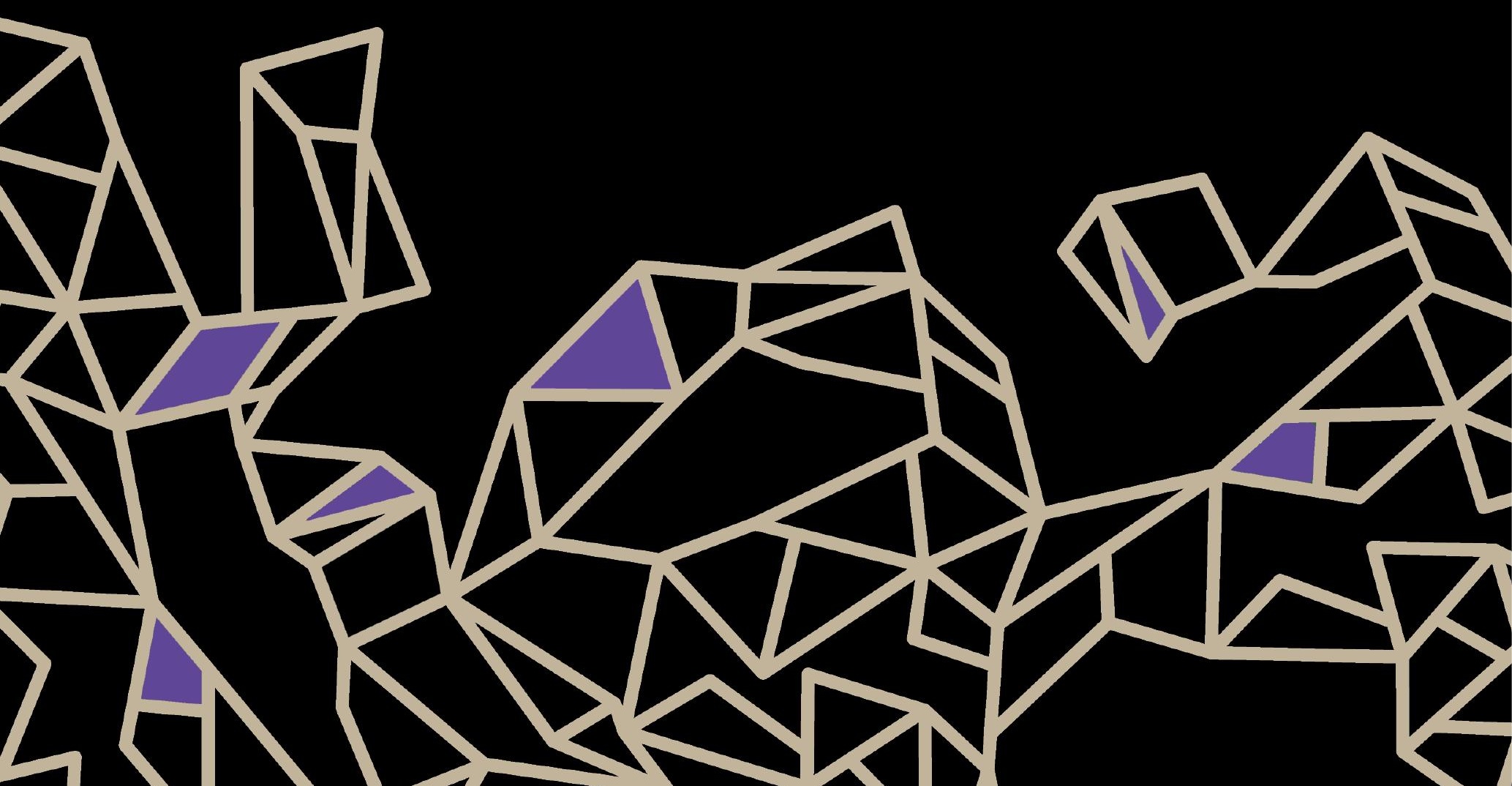




\section{Resumo}

O presente texto apresenta o novo espetáculo NEMMOKNA, dirigido por Susanne Linke, para o Ensemble do Trier Theater na Alemanha, que investiga, por meio de uma dramaturgia do corpo autoral, algumas formas de chegar, o se apresentar, o estar aqui e as lembranças de outros lugares já visitados. Em cena são vistas pessoas de diferentes lugares, que falam diferentes idiomas e, juntas, inauguram novos espaços cênicos com uma dança visceral. Neste artigo, a nova criação de Linke encontra esteio nas práticas dos pioneiros da German Dance, em diálogo com artistas e autores do século XX e XXI.

Palavras-chave: German Dance, Tanztheater, Susanne Linke, Theater Trier, Coreografia.

\section{Abstract}

This paper presents the new performance NEMMOKNA, directed by Susanne Linke for the Ensemble of the Trier Theater in Germany. The piece investigates, by a dramaturgy of the authorial body, some forms of arriving, the "introducing yourself", the "being here", and the memories from other places already visited. On stage, the audience can see people from different places, who speak different languages and, together, inaugurate new scenic spaces with a visceral dance. In this paper, Linke's new creation finds support on the practices of German Dance pioneers, in dialogue with artists and authors from the 20th and 21st centuries.

Keywords: German Dance, Tanztheater, Susanne Linke, Trier theater, Choreography.

Im Grunde reist man am besten, indem man füh/t. ${ }^{1}$

Fernando Pessoa

Chegar a um novo lugar não é fácil, tampouco somente uma grande aventura, exige dos envolvidos procura, observação e entrega. Dentro desse

1 "Fundamentalmente, viaja-se melhor pelo sentimento." 
pensamento a coreógrafa Susanne Linke², uma das mais importantes protagonistas da dança teatral alemã contemporânea (Tanztheater ${ }^{3}$ ), chegou, em setembro de 2015, a sua nova estação na cidade de Trier ${ }^{4}$ (Tréveris) na Alemanha, para assumir as funções de diretora artística e coreógrafa do setor de dança do Theater Trier, e para escrever novas páginas na história da dança mundial.

Susane Linke relatou, com muito bom humor, após a estreia ${ }^{5}$ no Theater Trier: "eu tenho idade para estar aposentada", mas que "foi difícil dizer não" quando Karl Sibelius, o diretor geral e administrativo do teatro, entrou em contato com a ideia do projeto: trazê-la como diretora do setor de dança, criar um novo Ensemble com bailarinos internacionais e bem preparados, e, ao longo de aproximadamente três temporadas, envolver o teatro, o elenco e a cidade com uma dança de vanguarda.

Ao longo de sua trajetória, Susanne Linke desenvolveu novas formas de movimentação e um caminho muito próprio, no qual seus movimentos são cheios de controle, contenção e de uma enorme precisão. Destacam-se duas estações de referência no período de sua formação, sendo a primeira a escola em Berlim de Mary Wigman6, a grande pioneira da dança de expressão, que priorizava em seus ensinamentos a exatidão na maneira de agir com as formas e seus conteúdos, com os sentimentos percebidos durante a realização de um movimento e a relação com o espaço ${ }^{7}$. A seguinte estação de

2 Susanne Linke (Lunenburg, 1944), dançarina, coreógrafa, diretora e pedagoga alemã de renome internacional. É juntamente com Pina Bausch (1940-2009) e Reinhild Hoffmann (1943) uma das grandes inovadoras do Tanztheater alemão.

3 Tanztheater: movimento de dança que ocorreu na Alemanha a partir de 1932, sua característica foi a transcendência da técnica do balé clássico utilizando-se da dramaticidade do teatro. Teve como precursor o coreógrafo e pedagogo Kurt Jooss (1901-1979), e entre seus seguidores mais conhecidos, que transitam na contemporaneidade, encontramos as coreógrafas Pina Bausch (1940-2009), Reinhild Hoffmann (1943) e Susanne Linke (1944).

4 Trier ou em português Tréveris é uma cidade histórica e também a mais antiga cidade alemã, localizada no estado da Renânia-Palatinado, às margens do rio Mosela, na divisa com Luxemburgo e o norte da França.

5 Estreia de NEMMOKNA, 30 jan. 2016. Disponível em: <https://youtu.be/lvQOJRbsRkM>. Acesso: 10 mar. 2016.

6 Mary Wigman (1886-1973) foi uma bailarina, coreógrafa e pedagoga alemã. É o principal nome associado ao pioneirismo da dança de expressão. As obras de sua autoria, como $A$ dança da Bruxa, permanecem emblemáticas até a contemporaneidade.

7 Segundo Pereira (2010), sentimento de vibração, "Vibratogefühl", chama-se a movimentação nos trabalhos desenvolvidos por Wigman, em que a parte inferior do corpo relacio- 
aprendizado para Linke foi a Folkwang Hochschule ${ }^{8}$, em Essen, onde buscou, nos ensinamentos dos professores Jean Cébron ${ }^{9}$ e Hans Züllig ${ }^{10}$, a beleza, a sutileza, o polimento da forma e, especialmente, a precisão nos trabalhos de pés e pernas. Essa formação complementar, na tradicional escola de Essen, trouxe um olhar centrado na forma e na técnica desenvolvida por Linke, mas não a afastou de seu impulso inicial de criação, tampouco de sua essência. Desde o início, Susanne Linke pretendeu encontrar uma linguagem para a qual fosse necessária uma técnica sólida, muita precisão, que traduzisse o que o seu corpo pretendia falar e que abrangesse para além da forma.

na-se com a terra, a parte superior do corpo relaciona-se com o céu e, entre essas duas partes, deve existir uma tensão que vibra com todas as energias, com todas as dinâmicas e, assim, dá-se um resultado no espaço.

8 Folkwang Hochschule, localizada na Alemanha, na cidade de Essen, na Renânia do Norte (Vestfália), foi fundada em 1927 como escola onde os estudantes se especializavam em música, teatro e dança. Atualmente existem novos cursos como Design e níveis de pós-graduação, e a escola (Hochschule) foi elevada à categoria de universidade. $\mathrm{O}$ departamento de dança foi, inicialmente, dirigido por Kurt Jooss. Entre seus estudantes ilustres encontraremos Pina Bausch (1940-2009), Susanne Linke (1944) e Reinhild Hoffmann (1943). Além disso, a Companhia Internacional de Dança Folkwang Tanz Studio (FTS), fundada por Kurt Jooss (1901-1979), é sediada na escola até os dias de hoje.

9 Jean Cébron (1927) nasceu em Paris, onde recebeu suas primeiras aulas de dança clássica (1945-1947) de sua mãe Mauricette Cébron, solista e professora na Ópera de Paris. Estudou com Sigurd Leeder, Alfredo Corvino, Kurt Jooss, entre outros. Foi solista e professor no Ballet Nacional de Santiago do Chile e no Folkwang Ballett de Essen. Foi professor e coreógrafo na José Limon Company de New York e na Dansskolar de Estocolmo, Suécia. Também foi professor em diferentes instituições e centros de dança moderna em diversas partes do mundo. Em 1976 foi nomeado professor de dança moderna na Folkwang Hochschule Essen, Folkwang Tanz Studio (FTS) e do Tanztheater Wuppertal, na ocasião ambos sob a direção de Pina Bausch. O seu ensinamento baseia-se no método Jooss-Leeder em conjugação com a técnica Cecchetti, integrados a sua pesquisa autoral.

10 Hans Züllig (1914-1992 ) iniciou seus estudos na escola das irmãs Wanda e Herta Bentele em St. Gallen, Suíça. Sua formação profissional aconteceu entre 1931 e 1934 com Kurt Jooss e Sigurd Leeder na Escola Folkwang, em Essen, e em Dartington Hall, na Inglaterra, quando, durante a Segunda Grande Guerra, o departamento se transferiu para lá. Foi "o jovem" na peça imortal de Jooss A Mesa Verde (1932), e permaneceu na companhia Ballets Jooss até 1947. A seguir, dançou no Sadler em Londres (1948-1949) e, outra vez como solista (1951-1953), na Folkwang Dance Theatre em Essen. Em 1954 ele seguiu Jooss como solista e segundo mestre de balé, de 1956 até 1961 foi bailarino, coreógrafo e professor na Universidade de Santiago de Chile. De 1968 a 1983 chefiou, com o título de professor, o Departamento de Dança e o Folkwang Tanz Studio (FTS), formador da maioria dos protagonistas do Tanztheater alemão. Foi de 1973 até o seu falecimento (1992) professor no Tanztheater Wuppertal Pina Bausch. Como professor convidado trabalhou na França, Itália, Espanha, Holanda, China, Costa Rica, Hong Kong, Taiwan, entre outros países. Hans Züllig foi um dos professores mais influentes na Folkwang Hochschule e um dos mediadores mais importantes da dança moderna no século XX. 
Sua obra inclui mais de 30 criações para diferentes companhias de dança internacionais, entre elas a Ópera de Paris, o Netherlands Dance Theater, a José Limón Company de Nova York e o Grupo Corpo de Belo Horizonte. Além disso, compôs coreografias solos ${ }^{11}$ que fazem parte de um dos capítulos mais significativos de sua carreira. Os solos são seus pontos-âncora, em que a coreógrafa pôde certificar-se de suas buscas mais profundas e que the projetaram a uma posição de destaque no cenário internacional da dança. A partir de suas minuciosas investigações, determinou inovações cênicas, como o uso de objetos e tecidos que dialogam como seus partners, e que têm servido de inspiração para as novas gerações.

\section{NEMMOKNA}

O título em alemão, da primeira peça para o recém-criado Ensemble, é NEMMOKNA e a palavra, inicialmente, parece não ter nenhum significado na língua de Goethe. Ocorre que o nome NEMMOKNA está escrito da direita para a esquerda, ou seja, ao contrário. Se for escrito da esquerda para a direita, como é comum no ocidente, em alemão a palavra é "ANKOMMEN", e, traduzindo para o português, significa "CHEGAR".

E é sobre as formas de chegar, das chegadas, do se apresentar, do estar aqui, das lembranças de outros lugares já visitados que a coreógrafa, junto aos coautores da peça, os bailarinos, quer tratar. Longos caminhos são percorridos, o cansaço, o encontro casual entre pessoas de diferentes lugares, as descobertas, o descobrimento de um novo espaço e também de um novo palco cênico.

Cenas $1,2,3,4,5,6,7 \ldots$

Em um palco enorme, vazio, apenas com níveis diferentes, com pouca luz e coberto de fumaça cênica, avistamos o vulto de uma pessoa, a bailarina

11 Uma de suas obras mais conhecidas é o solo Im Bade wannen ("Na banheira"), de 1980. A temática do solo gira em torno da frustração e do aborrecimento que uma mulher pode sentir no banheiro. Utilizando-se de gestos do cotidiano, a coreógrafa transforma a banheira em partner que ganha, ao longo da peça, quase vida própria. Além de atingir um momento extremamente poético, a coreógrafa também mostra uma possibilidade de transcendência dentro de seu dia a dia. De um lado, encontramos um realismo com um olhar bem direcionado na dificuldade, de outro, a capacidade de transcendência. 
francesa Héloïse Fournier ${ }^{12}$, que aparece, inicialmente, realizando uma movimentação muito lenta e densa. Ela vem ganhando espaço, vindo de muito longe, como alguém que já andou muito para chegar até esse aqui e agora. $O$ olhar do público está concentrado nessa figura quando, lentamente, o fosso do proscênio sobe, trazendo todo o elenco, que está deitado. $O$ grupo atinge o nível do palco e, apesar de ficar por um tempo movimentando-se muito devagar, um a um vai ganhando vida, energia e realizando movimentações pelo chão, que têm seu ápice no fundo do palco. Chegaram ou já estão partindo para outros lugares desconhecidos?

É Agamben (2009) que poeticamente nos conduz nesta passagem:

É nesse sentido que se pode dizer que a via de acesso ao presente tem necessariamente a forma de uma arqueologia que não regride, no entanto, a um passado remoto, mas a tudo aquilo que no presente não podemos em nenhum caso viver e, restando não vivido, é incessantemente relançado para a origem, sem jamais poder alcançá-la. (p. 70)

Nesse momento percebemos que eles estão vestidos com roupas estilizadas, que mesclam partes de figurinos antigos, peças mais modernas e outras difíceis de precisar. Nos figurinos aparecem acessórios que lembram a gola da roupa de um "arlequim" ou a releitura de um minifraque, mas, principalmente, roupas usadas em ocasiões festivas ou especiais. Para o que está sendo apresentado na cena, consideramos novamente preciso o pensamento de Agamben (Ibid.):

Aquilo que define a moda é que ela introduz no tempo uma peculiar descontinuidade, que divide a sua atualidade ou inatualidade [...]. O tempo

12 Héloïse Fournier nasceu em 1982 na França. Estudou dança e saxofone no Conservatório d'Orléans. Em seguida, concentrou-se nos estudos de dança, inicialmente em La Rochelle e, em 2002, na Folkwang Hochschule Essen. Durante os seus estudos trabalhou com Susanne Linke e Samir Akika. Em 2007 trabalhou ao lado de Max Merker e ganhou o Prêmio do Júri do 100ํFestival de Berlim. Entre 2007 e 2012 foi membro do Tanztheater Bremen sob a direção de Urs Dietrich. Na sequência, trabalhou com coreógrafos convidados, como Emanuel Gat, Tero Saarinen, Rami Beer, Henrietta Horne e Reinhild Hoffmann. No Theater Osnabrück foi vista na temporada 2012/13 em Leonce e Lena como Rosetta. No Teatro da Ópera de Leipzig dançou O Anel de Wagner, dirigido por Rosamund Gilmore (2013). Em 2013, reconstruiu e dançou o solo Four (1992) de Reinhild Hoffmann. Entre 2012 e 2015 trabalhou regularmente como professora de dança e membro da Companhia De Looper em vários projetos escolares em Bremen. Desde setembro de 2015, integra a Companhia Susanne Linke no Trier Theater. 
da moda está constitutivamente adiantado a si mesmo e, exatamente por isso, também sempre atrasado, tem sempre a forma de um limiar inapreensível entre um "ainda não" e um "não mais". (p. 66-67)

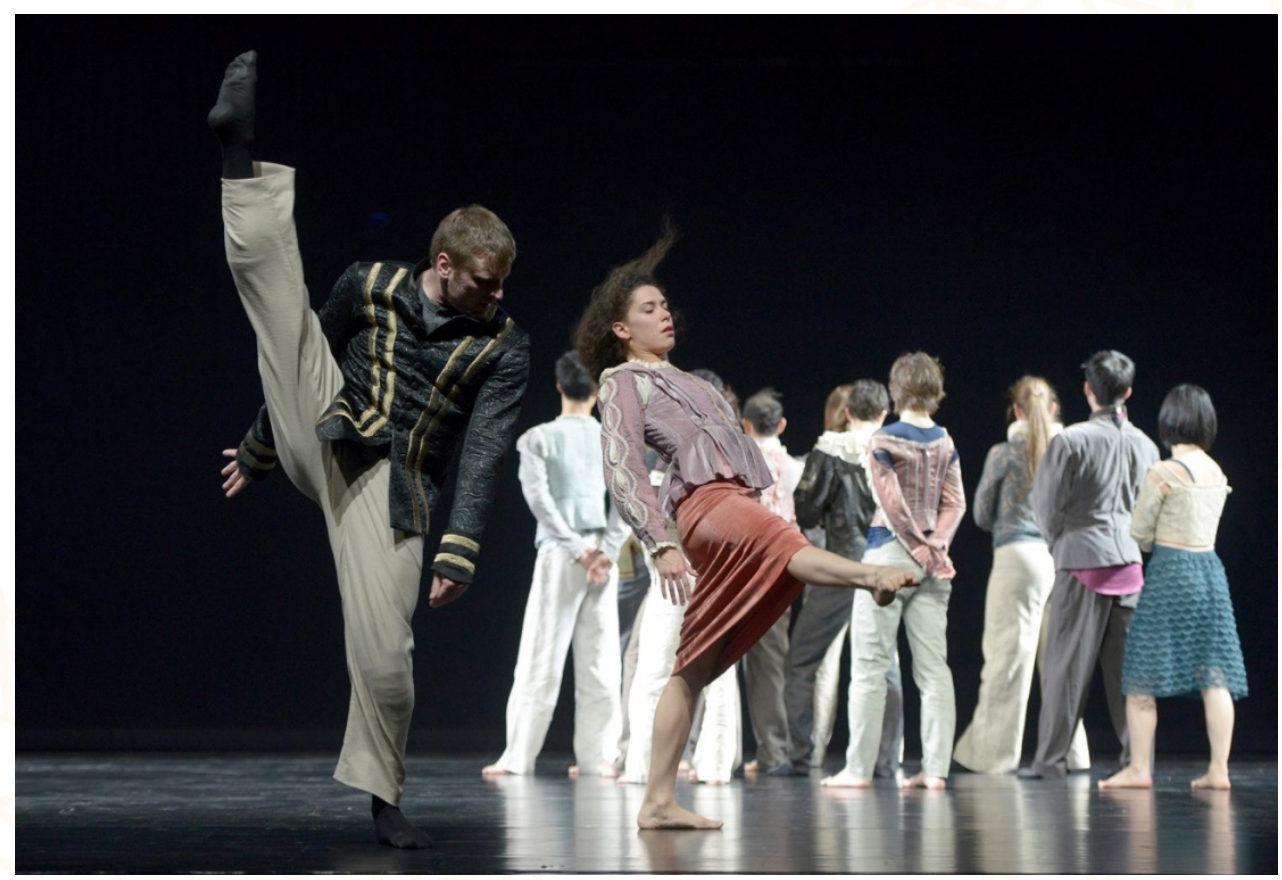

Figura 1 - Roberto Przybyl, Luiza Braz Batista e elenco.

Foto: Coleção Trier Theater ${ }^{13}$.

O que acontece seria um primeiro encontro com a cidade, com o prédio do teatro, com as pessoas desse lugar?

Então, quando todos estão reunidos como um grande grupo, a bailarina alemã Mareike Franz ${ }^{14}$ destaca-se dele e faz um pequeno solo, no qual brinca com diferentes palavras e alguns provérbios que irão acompanhar outras cenas da peça. Na sequência, todo o elenco tira a parte do figurino que poderia ser associado a um casaco, quebrando um pouco a elegante formalidade dos trajes que estavam usando.

13 Todas as imagens estão disponíveis em: <https //m.facebook.com/ulf.frotzschner/posts>. Acesso em: 20 mar. 2016.

14 Mareike Franz (Alemanha, 1984) estudou dança na Palucca Schule, em Dresden, e na Folkwang Universität, Essen. Tem dançado como solista em obras de Susanne Linke e, também, no Ballet Kiel, no Folkwang Tanzstudio (FTS), como convidada no Tanztheater Wuppertal Pina Bausch e em outras produções como freelancer. Mareike Franz é uma ex-bolsista do Jungen Akademie der Künste Berlim, e, nos últimos anos, tem ministrado workshops em dança e improvisação, escreve poesia e prosa, e está se interessando por teatro físico e pelo trabalho de clown. Desde setembro de 2015, integra a Companhia Susanne Linke, no Trier Theater. 


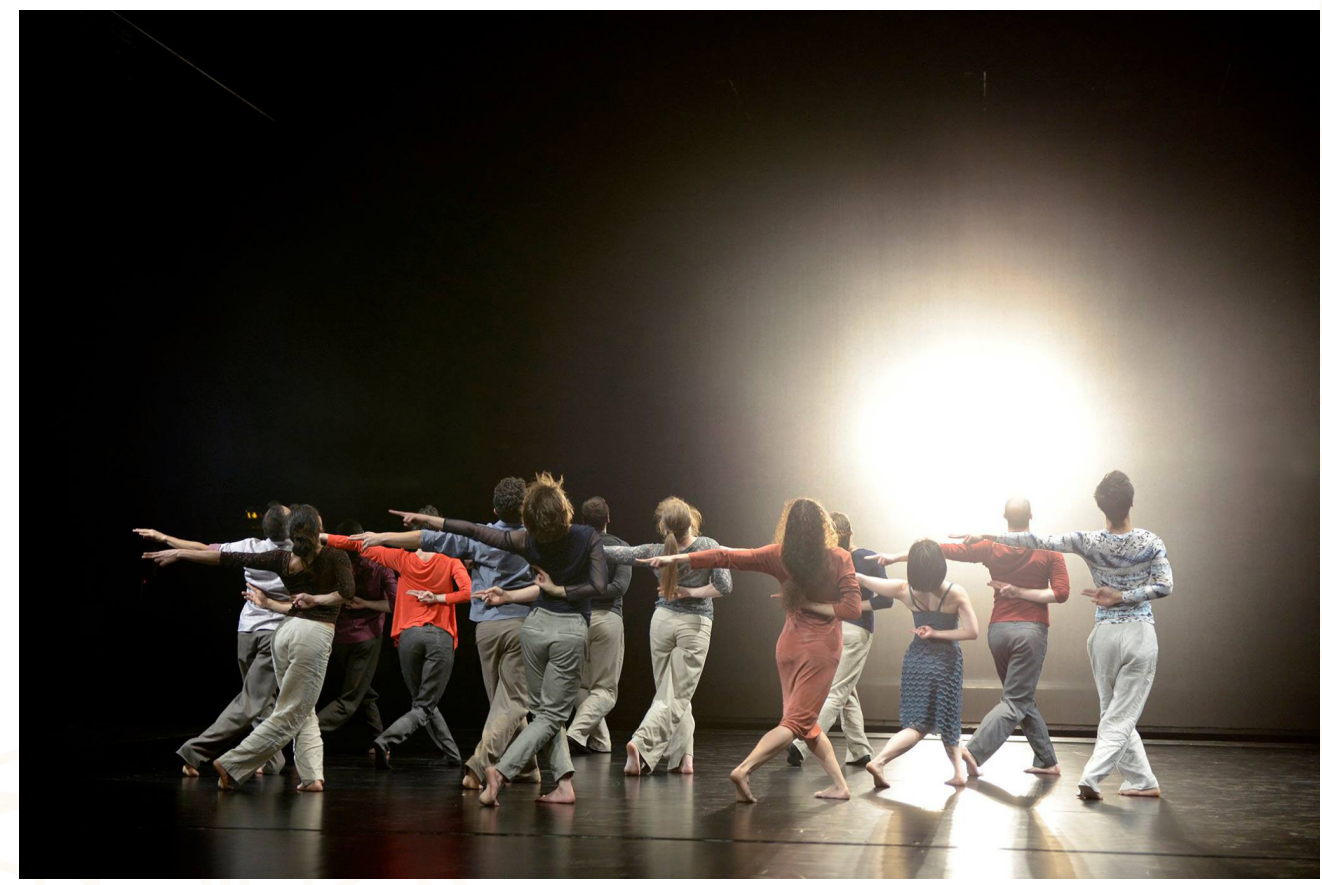

Figura 2 - Elenco. Foto: Coleção Trier Theater.

Com esse "despir", todo o elenco entra em uma grande dança muito agitada e com uma movimentação bastante pessoal. Percebe-se que foram trabalhadas unidades de movimento e que cada intérprete incluiu suas próprias habilidades e estilos de movimentação.

Associamos esse fato às palavras de Grotowski (apud SCHECHNER, 2009) "O ator é pelo menos em parte, ao mesmo tempo criador, modelo e criação. Ele não deve ser imodesto, pois leva ao exibicionismo. Ele deve ter coragem, mas não apenas a coragem de se exibir - uma coragem passiva, podemos dizer - e sim a coragem dos que se desarmam, a coragem de se revelar" (p. 333).

Compreende-se a sensibilidade da coreógrafa Susanne Linke que, a partir de sequências de movimentos criadas por ela e assimiladas pelos bailarinos, dá espaço e os encoraja a se revelarem. Então, em uma próxima etapa, permite que eles incluam suas movimentações pessoais e, sob sua regência, irão compor um patchwork coreográfico muito complexo, dinâmico, sempre surpreendente e revelador.

Esse modo operante no processo de criação de Linke para NEMMOK$N A$ nos faz lembrar, de certo modo, que, desde os primórdios, os dançarinos 
gregos realizavam e praticavam suas danças respeitando inúmeras regras tradicionais, todavia era confiado a esses dançarinos a liberdade para que introduzissem o quanto de invenção quisessem. Tradição e modernidade, conversando por meio de alguns denominadores comuns.

"Assim, o mundo antigo no seu fim se volta, para se reencontrar, aos primórdios: a vanguarda, que se extraviou no tempo, segue o primitivo e o arcaico" (AGAMBEN, 2009, p. 70).

\section{Encontros e desencontros}

"Onde eu estou, por que eu estou aqui, o que eu vejo?"15 são as grandes questões que Susanne Linke pediu que os seus bailarinos se ocupassem e respondessem em seu idioma materno, em NEMMOKNA.

Entre encontros, desencontros e despedidas vemos em cena um casal taiwanês, Ching-Yu Chin ${ }^{16}$ e Kyungwoo Kwon ${ }^{17}$, realizando uma movimentação muito precisa, que acontece nos diferentes planos do palco. Cada movimento nasce do impulso de suas vozes, de palavras, de textos e de jogos que se sucedem em uma língua desconhecida para grande parte do público, o chinês. Acredita-se que não importa muito para a coreógrafa que o público compreenda o significado do que é dito, e sim que se deixe envolver nas ações, na fonte dos impulsos, na musicalidade das palavras, nas frases construídas e no espaço que essa movimentação percorre. Em certo momento, complementam a cena o venezuelano Darwin José Diaz Carrero ${ }^{18}$, o chileno

15 Original: Wo bin ich denn, warum steh ich hier, was sehe ich? (Tradução nossa).

16 Ching-Yu Chin, natural do Taiwan. Desde setembro de 2015, integra a Companhia Susanne Linke no Trier Theater como guest dancer.

17 Kyungwoo Kwon, natural do Taiwan. Desde setembro de 2015, integra a Companhia Susanne Linke no Trier Theater guest dancer.

18 Darwin José Diaz Carrero nasceu na Venezuela e estudou na Universidade de Dança em Caracas. Em 2005 recebeu uma bolsa de intercâmbio acadêmico para estudar dança moderna no Folkwang Universität der Künste, Essen, Alemanha. A partir de 2009, até fevereiro de 2014, dançou na Folkwang Tanzstudio (FTS), em Essen. Nesse período trabalhou com diferentes coreógrafos como Pina Bausch, Susanne Linke, Rodolpho Leoni, Samir Akika, Urs Dietrich, Marc Sieszkarek, Daniel Goldin, Chikako Kaido, Anna Holter, Fang-Yu Shen, entre outros. Desde setembro de 2015, integra a Companhia Susanne Linke no Trier Theater. 
Yves Ytier ${ }^{19}$, o colombiano Victor Alfonso Zapata Cardenas ${ }^{20}$, três bailarinos procedentes de países de língua espanhola que constroem um jogo combinando palavras e movimentações baseadas no "por que estar aqui".

Comovente são as ações de Sergey Zhukov ${ }^{21}$, atuando com movimentos dramáticos, tensos e muito precisos. $\mathrm{O}$ bailarino parece ter partido de outro lugar, para chegar não se sabe muito bem onde. $O$ texto é dito em sua língua materna, o russo, com palavras que movem, removem, comovem-nos e dão ritmo e beleza nas combinações que seu corpo vai descrevendo pelo espaço de um modo muito visceral. Igualmente, a bailarina polonesa Lucyna Zwolinska ${ }^{22}$ participa da cena, movendo-se com precisão em diálogo com as palavras de um texto falado na língua de seu país de nascimento.

19 Yves Ytier nasceu em Santiago do Chile em 1988. Com seis anos de idade iniciou seus estudos de violino e, durante a sua formação, teve contato com dança, teatro e música. Em 2011 completou seus estudos de violino na Pontifícia Universidade Católica do Chile. Durante 2008 e 2009 estudou dança contemporânea em Santiago com Raymond Hilbert e Yasna Vergara, entre outros. Em 2011 reiniciou os estudos na Universidade de Folkwang, em Essen, onde se graduou em junho de 2015. Na mesma universidade frequenta, desde 2014, as classes de violino de Mayumi Hirasaki, mestre em barroco. Yves Ytier combina seu trabalho como dançarino e músico e tem tomado parte em vários projetos interdisciplinares, participado em festivais e master classes no Chile, Inglaterra, Alemanha, Hollanda e Portugal. Integra o ensemble Gradus ad Parnassum de música antiga. Desde setembro de 2015, integra a Companhia Susanne Linke no Trier Theater, como estagiário.

20 Victor Alfonso Zapata Cardenas nasceu em 1988, em Medellín, Colômbia. Em 2003, começou sua formação clássica com Margarita Acevedo, em Cúcuta. Em 2010, formou-se na Folkwang Universität der Künste e, em 2012, concluiu seu mestrado em dança na mesma escola. Integrou as companhias de dança da Deutschen Oper Am Rhein (Dusseldorf), Oper Dortmund, Oper Bonn, Tanzmoto, entre outras. Dançou peças de Rodolpho Leoni, Henrietta Horn, Mark Sieczkarek, Susanne Linke e no Tanztheater Wuppertal Pina Bausch. Desde setembro de 2015, integra a Companhia Susanne Linke no Trier Theater.

21 Sergey Zhukov nasceu no Cazaquistão. Estudou dança na Folkwang Universität der Künste e formou-se em 2009 com o prêmio Folkwang. De 2008 a 2014 foi membro da Folkwang Tanzstudio (FTS) e, desde 2006, foi dançarino convidado do Tanztheater Wuppertal Pina Bausch. Trabalhou com coreógrafos como Susanne Linke, Urs Dietrich, Rodolpho Leoni, Mark Sieczkarek, Henrietta Horn, Chikako Kaido, Ben J. Riepe, Va Wölfl, entre outros. Desde setembro de 2015, integra a Companhia Susanne Linke no Trier Theater.

22 Lucyna Zwolinska nasceu na Polônia, estudou na escola de balé em Beuthen e, mais tarde, na Fachschule für Musik und Darstellende Kunst, em Frankfurt am Main. Em 2006, dançou na Forsythe Companhia como bailarina convidada e, em 2007, em Augsburg. De 2010 a 2015 integrou a Companhia do Teatro da cidade de Augsburg na Alemanha, dançando em peças de William Forsythe, Itzik Galili, Johan Inger, Marguerite Donlon, entre outros. Em 2012, com a coreografia Drogas, venceu o Choreografen Wettbewerb, em 2013 recebeu seu $2^{\circ}$ prêmio, o de apresentação na Tanzmesse NRW, e o prêmio do público. Desde setembro de 2015, integra a Companhia Susanne Linke no Trier Theater. 


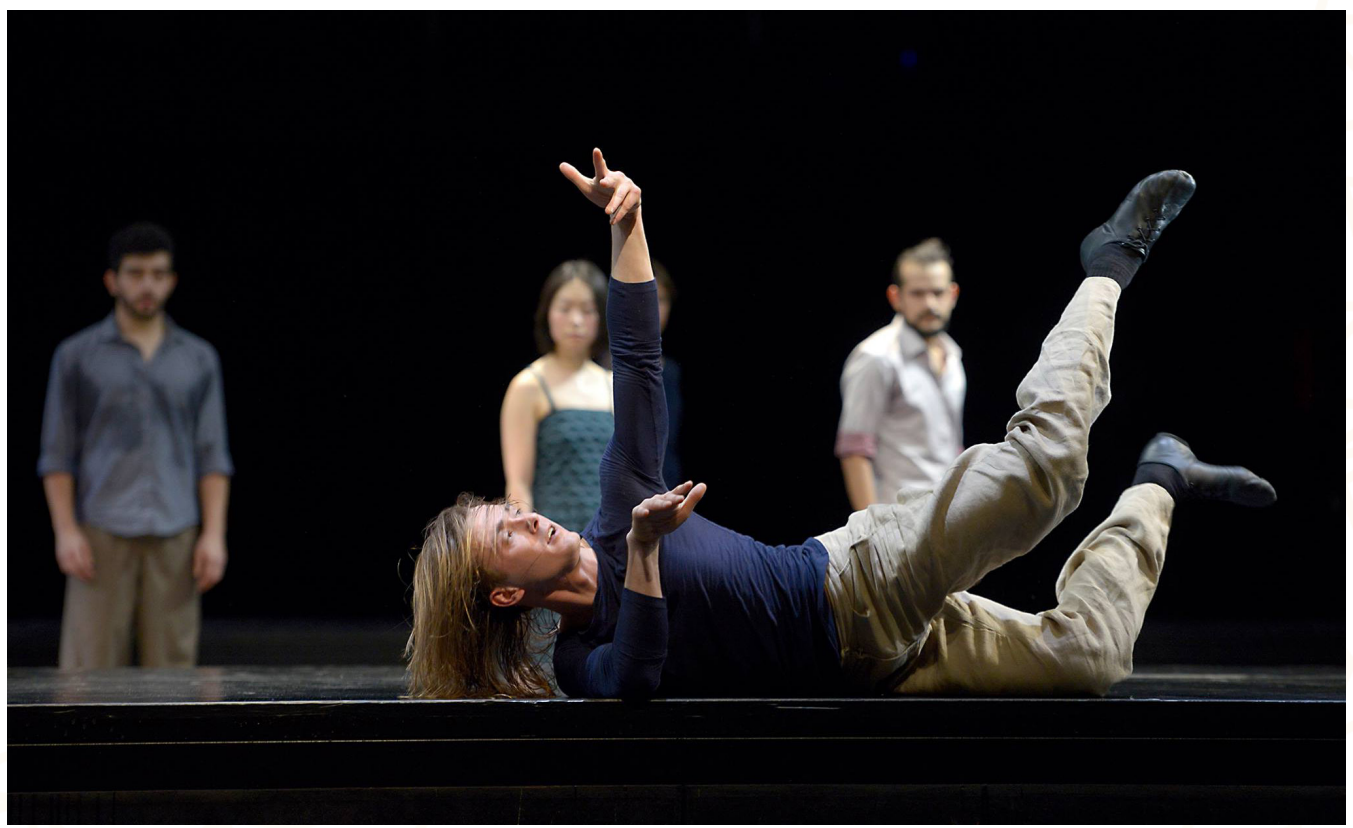

Figura 3 - Sergey Zhukov e elenco. Foto: Coleção Trier Theater.

É interessante pensar nas palavras do coreógrafo africano, nascido em Benin, Koffi Kôkô (2005), com quem Linke fez um trabalho colaborativo intitulado Mistral (2014), no que diz respeito a uma dança que pode ou não ser tocante:

Não existe dança boa ou má dança. Existe apenas dança. E esta dança pode me dizer alguma coisa ou não me dizer nada. A conversa aqui é sobre um tipo de movimento que não tem nada que ver com critérios estéticos ou conceitos. Um movimento é verdadeiro quando o seu ponto de partida vem do interior do ser, ele pode ser então um movimento muito simples, e até o contrário de um movimento belo. Porque o que é bonito não é necessariamente o que é correto. (p. 64-65, tradução nossa ${ }^{23}$

E é essa a ideia que Susanne Linke, através de seu Ensemble, faz o público perceber, em todas as movimentações que são realizadas pelo elenco. Cada um oferece o que tem de melhor para essa dança-celebração que está sendo construída. Nenhum movimento é obvio ou gratuito, a audiência vai sempre sendo surpreendida.

23 No original: "Es gibt keinen schönen oder schlechten Tanz. Es gibt nur einen Tanz. Und dieser Tanz kann zu mir sprechen oder er kann nicht zu mir sprechen. Die Rede ist hier von einer Art der Bewegung, die nicht mit äthetischen Kriterien oder Begriffen zu fassen ist. Eine Bewegung ist wahr, wenn sie ihren Ausganspunkt innen hat". 
Outro mestre que inspirou Linke, Kurt Jooss ${ }^{24}$, tinha, em sua metodologia, a crença de que é muito importante "lapidar o material que o intérprete já traz em seu corpo dando a ele ferramentas," que a autora deste texto entende como técnica ou aperfeiçoamento "para que o intérprete se expresse com precisão e verdade" (apud MARKARD, 1985, p. 76).

Na contemporaneidade, raros são os coreógrafos que abordam a dança com um olhar que passe pelo humor, pois além de ser um elemento bastante arriscado, é muito importante que a cena não perca a sua mensagem, independente da reação da plateia. NEMMOKNA traz um pouco de humor no jogo de palavras, que, como salientamos anteriormente, são muitas vezes faladas em idiomas desconhecidos pela maioria das pessoas da audiência. As ações realizadas e as posições que são trocadas com certa velocidade seguem a musicalidade orientada, dessa vez, partindo da poesia de Daniil Kharms (1929) ${ }^{25}$ : "Bom, então eu quero contar todos os itens com os meus 10 dedos", falado em língua alemã pela bailarina Mereike Franz, por Paul Hess ${ }^{26}$, ambos alemães, e pela nicaraguense Elisa Marschall ${ }^{27}$.

24 Kurt Jooss (1901-1979), bailarino, coreógrafo e pedagogo. Foi aluno e assistente de Laban, e esteve muito próximo da dança de expressão dirigida pela colega Mary Wigman. É considerado o precursor da dança teatral ou Thanztheater. Tentou integrar em suas obras a transdisciplinaridade entre balé clássico, artes visuais e teatro. Foi fundador do departamento de dança da Folkwang Hochschule de Essen, inovando em sua proposta pedagógica. Criou e dirigiu o Ballet Jooss e, por último, o Folkwang Tanz Studio (FTS). Sua obra imortal é a A Mesa Verde (1932), que previa todos os horrores da Segunda Grande Guerra, satirizava a hipocrisia dos diplomatas e donos do poder, mostrava a dor, a violência, mantendo-se tão atual até os dias de hoje.

25 Original: Gut dann will ich mit zehn Fingern alle Gegenstande zähln (tradução nossa). Daniil Kharms (1929-1942), poeta russo preso em Leningrado em 1942 que, após ter praticado greve de fome, morreu na prisão. Somente com a Perestroika seu trabalho se tornou público.

26 Paul Hess nasceu na Alemanha. É coreógrafo, diretor, dançarino e cantor. Formou-se na Folkwang Universität der Künste em Dança e Coreografia. Desde 2008 tem criado, com êxito, suas próprias coreografias. Participou de peças e instalações dirigidas por Mark Sieczkarek, Daniel Goldin, Anna Konjetzky, Jerome Bel, Rolf Dennemann, Ed Atkins, entre outros. Integrou, entre outras, as companhias: Tanztheater Münster, Renegado e Artscenico. Entre 2008 e 2015 foi bailarino convidado do Tanztheater Wuppertal Pina Bausch e tomou parte no filme nomeado ao Oscar, de Wim Wenders, Pina. Juntamente com sua partner, Luiza Braz Batista, fundou o Coletivo de Artistas GALEO. Desde setembro de 2015, integra a Companhia Susanne Linke, no Trier Theater.

27 Elisa Marschall nasceu na Nicarágua. Estudou dança no Folkwang Universität, em Essen (Alemanha). Depois, aprofundou seus estudos em dança em Arnhem (Países Baixos). Ainda como estudante, teve a oportunidade de trabalhar com coreógrafos como Rodolfo Leoni, Mark Sieczkarek, Amos Ben-Tal, Roberto Tacs e Philip Taylor. Entre 2010 e 2015, trabalhou como dançarina freelancer com diferentes companhias, diretores e coreógrafos, 
A próxima cena é um divisor de águas, que se utiliza de um efeito cênico para mover a audiência da situação cômoda de observadora, relativamente estática, na qual, através de uma luz muito forte direcionada para a plateia, o jogo cênico é interrompido. O efeito poderia ser comparado a um grito, uma sacudida, uma anunciação acompanhada de uma música com sons mais duros e agressivos. A cena se constrói formando, no palco, dois níveis. As mulheres dançam no nível superior com cabelos soltos e movimentando muito o tronco e os braços. A utilização da parte superior do corpo como ponto de partida do movimento é uma característica bastante comum nas movimentações encontradas na dança teatral. Já as ações dos rapazes acontecem, na sua maioria, no plano baixo, pelo chão, finalizadas com saltos e com ações muito acrobáticas.

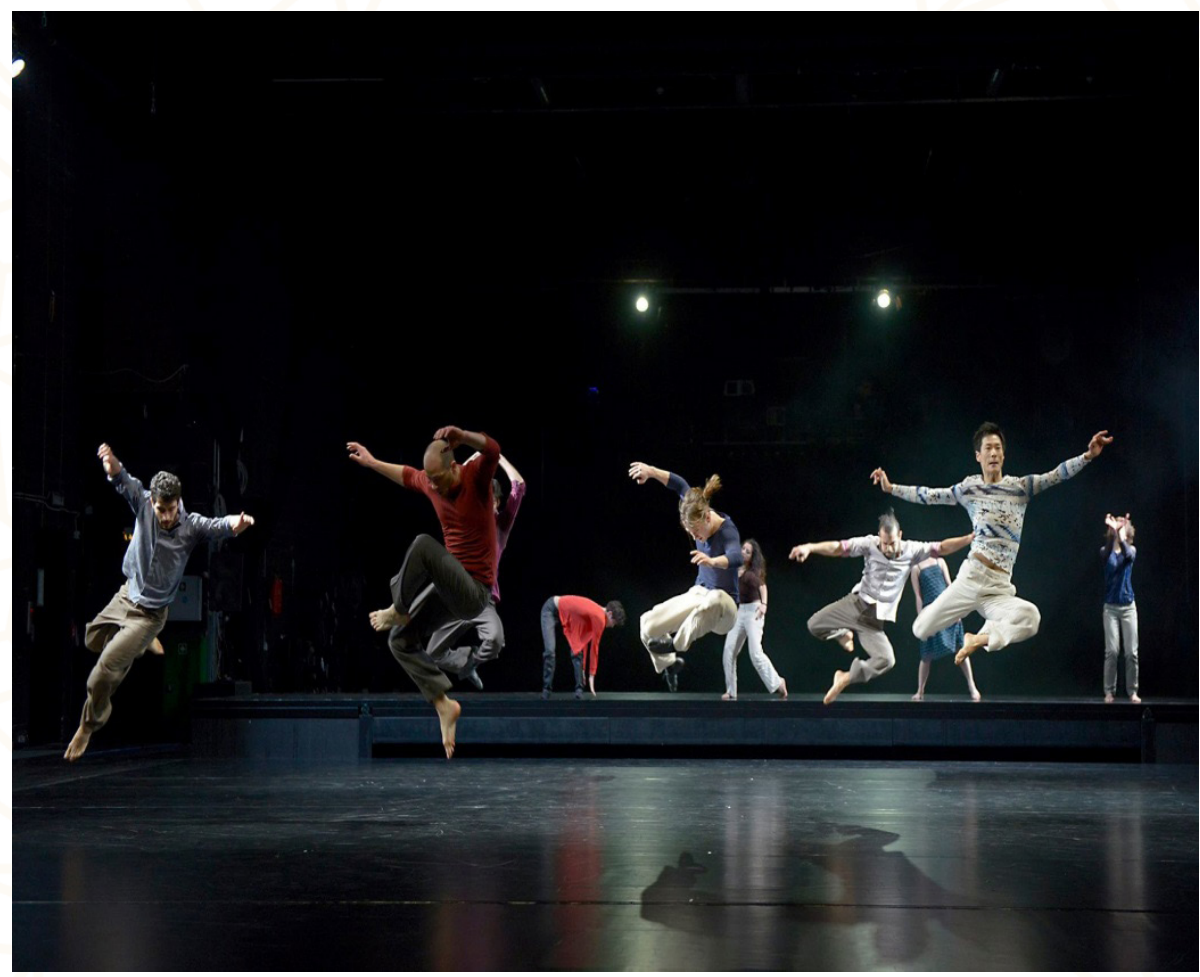

Figura 4 - Elenco. Foto: Coleção Trier Theater.

As ações realizadas em cena, pelos bailarinos, criam uma grande densidade até que todos deixam o palco vazio para o retorno da figura que

entre eles: Teatro der Klänge, Renegado Theatre, Anna Konjetzky, Carlus Padrissa, Philipp Stölzl, Mara Kurtoschka, Rolf Dennemann, Johannes Schmidt e Anna Holter. Desde setembro de 2015, integra a Companhia Susanne Linke, no Trier Theater. 
iniciou a peça, Héloïse Fournier, que irá mencionar e rever a movimentação da cena inaugural.

Nesse segmento, a bailarina senta-se em um dos desníveis do palco e realiza um solo muito sensível, no qual seu rosto está totalmente coberto pelos seus cabelos castanhos dourados. As ações realizadas são minimalistas, contidas, quase secretas. No final do solo, percebemos que ela não está sozinha, existe outra pessoa atrás dela, também com longos cabelos, só que castanhos mais escuros, que interage como se fosse uma sombra, um eco, (uma proteção?). Esse personagem é a bailarina brasileira Luiza Braz Batista $^{28}$, esguia, lânguida, silenciosa, partner, vestindo um longo manto. Da posição de sombra/partner, a bailarina ganha espaço cênico e passa a atuar na 1aㅡ pessoa, realizando uma dança sutil, cheia de memórias, que vai sendo escrita nos diferentes níveis do palco. Sua movimentação elegante, musicada pelos sons de seus sapatos de tap dance, uma vez ou outra, oferece à audiência o direito de quase também participar da cena, pelo menos com as suas próprias lembranças e associações.

28 Luiza Braz Batista é coreógrafa, dançarina e cantora. Nascida em Vitória, Brasil, começou sua carreira como bailarina muito jovem, no grupo de dança Primeiro Ato, em Belo Horizonte. Com 16 anos de idade recebeu seu primeiro prêmio como coreógrafa. Aos 19 anos se formou em dança na Folkwang Universität der Künste, em Essen, na Alemanha. De 2009 a 2015 trabalhou na companhia de dança Fokwang Tanzstudio (FTS). A partir de 2008 até 2015 atuou como dançarina convidada do Tanztheater Wuppertal Pina Bausch. Foi solista da peça emblemática de Susanne Linke Frauenballett e das peças Wind von West e Zweiter Frühling, de Pina Bausch, que não eram remontadas há mais de três décadas. Trabalhou com outros coreógrafos, tais como Emanuel Gat, David Hernandez, Suely Machado e Urs Dietrich. Como cantora, dançarina e coreógrafa, Luiza se destaca pela versatilidade, desenvolvendo seu próprio trabalho, sendo convidada para participar em festivais internacionais de música e de dança. Em 2014, fundou, juntamente com Paul Hess, o Coletivo de Artistas GALEO. Desde setembro de 2015, integra a Companhia Susanne Linke, no Trier Theater. 


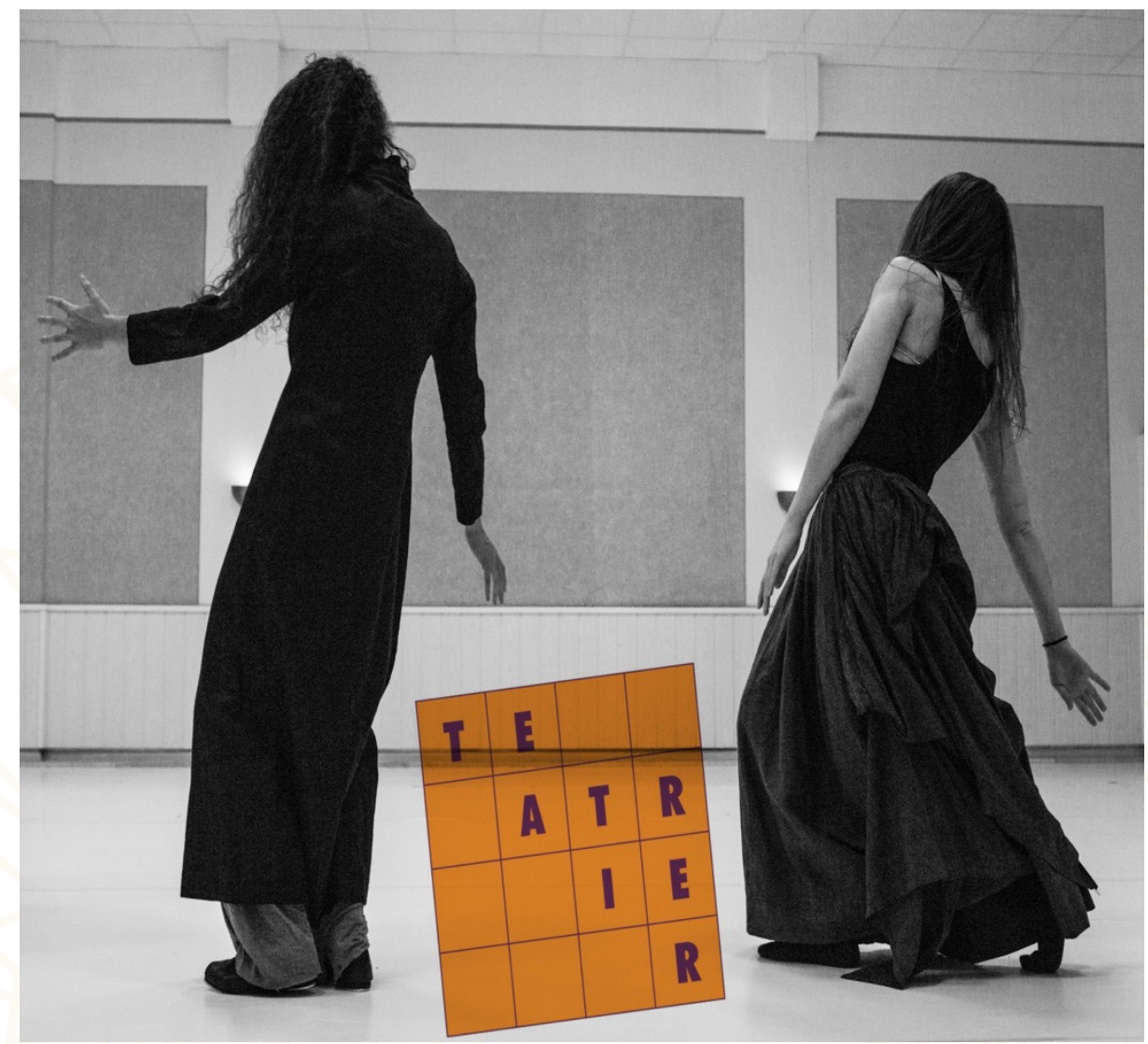

Figura 5 - Luiza Braz Batista e Héloïse Fournier. Foto: Coleção Trier Theater.

Susanne Linke valoriza a personalidade de cada dançarino. Acredita que o dançarino pode se incluir no movimento e criar novos movimentos ou executar, com pessoalidade, os movimentos que são pedidos. Observa-se ainda na sua obra, que o dançarino não usa o movimento apenas para se mover, mas, especialmente, para ter um subtexto, para entender o que ele próprio está fazendo no movimento.

A próxima cena oferece novos solos femininos realizados individualmente, outros ao mesmo tempo, sempre com movimentações muito pessoais e realizadas com precisão e intensidade. Segundo Pereira (2009), "Susanne Linke proporciona ao seu público a possibilidade de que seja visualizada uma transparência em suas criações, esse desejo de transparência é aliado nas suas obras com o físico, a técnica de dança e o espiritual” (p. 2).

Ao final da cena composta pelos solos femininos, temos outra vez a bailarina Luiza Braz Batista, que irá protagonizar uma das cenas mais tocantes de toda a peça. Usando um vestido vermelho que delineia muito bem a sua 
silhueta, compõe, com todo seu corpo e alma, um solo com música de jazz americano. Seus movimentos precisos e enormes parecem traduzir uma grande solidão, aquele tipo de solidão experimentada mesmo quando tem muitas pessoas por perto ou quando a pessoa chega a um novo lugar e se sente estrangeira. Ou talvez, ainda, a solidão de cada ser humano. Todos os movimentos parecem ter sido lapidados até serem sentidos no corpo da intérprete, na sua mais fina ramificação, mostrando-nos qual o caminho de que a emoção se serve através do corpo. Quando a cena atinge seu ápice dramático, a intérprete começa a ser seguida por um grupo de rapazes, que acabam interagindo com Braz Batista nos diferentes níveis e lugares do palco, realizando ações rápidas e cheias de dinamismo, quebrando o tom mais introspectivo da cena.

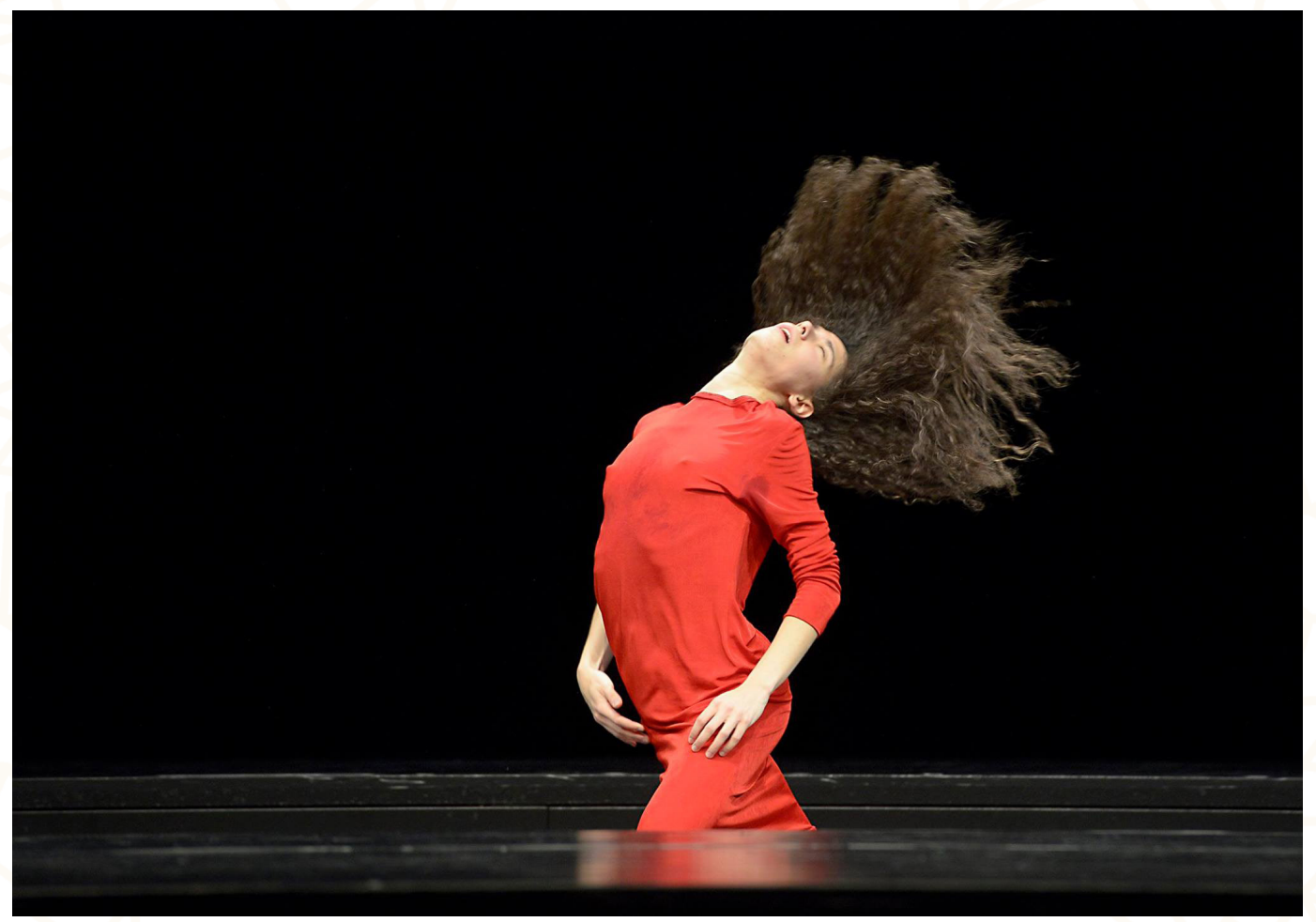

Figura 6 - Luiza Braz Batista. Foto: Coleção Trier Theater.

Ao longo deste texto temos chamado a atenção para a procedência de cada intérprete, por serem originários de diferentes países e pelo estranhamento das diferentes línguas faladas em cena. Assim, a dança teatral, que se utiliza da palavra, das canções e das memórias vividas pelos intérpretes, que tomam parte nas criações coreográficas, como mais uma de suas ferramen- 
tas, permite que os mesmos possam se comunicar nos diferentes idiomas falados, o que acaba sendo outra interessante contribuição para a peça aqui analisada. Vale ressaltar que a Alemanha é um país que nos últimos cinquenta anos, mesmo com a redução do número de companhias de dança na última década, nos teatros estatais, tem conseguido se manter aberta à contratação de artistas estrangeiros para os seus quadros profissionais.

Em NEMMOKNA, os intérpretes afinados falam uma mesma língua, a da dança, que a regente Susanne Linke consegue harmonizar e unificar, mesmo quando dá oportunidade para que cada intérprete represente a si mesmo.

Na sequência da peça, a próxima cena apresenta uma situação espacial muito nova, protagonizada em solo pelo bailarino Paul Hess, atuando em uma faixa do proscênio. No solo, Hess trabalha com movimentações acrobáticas, muito interligadas, cheias de precisão, onde também é possível reconhecer elementos do jogo de palavras realizado anteriormente com a poesia de Daniil Kharms, enfatizando os 10 dedos das mãos. A audiência mantinha-se totalmente concentrada nas ações do bailarino, que aconteciam no primeiro plano, e foi preciso algum tempo para se perceber que todo o restante do palco estava subindo, como um muro de uns três andares, acima do nível do chão. A cena é de uma grande plasticidade e força: o bailarino, agindo no primeiro plano em um espaço reduzido do palco quando a plateia inicia a avistar cabeças e mãos de todo elenco, que aparecem grudadas naquele muro. A seguir, eles avançam "em cima do muro" e olham para baixo, para Paul Hess, que parece muito pequeno e silencioso.

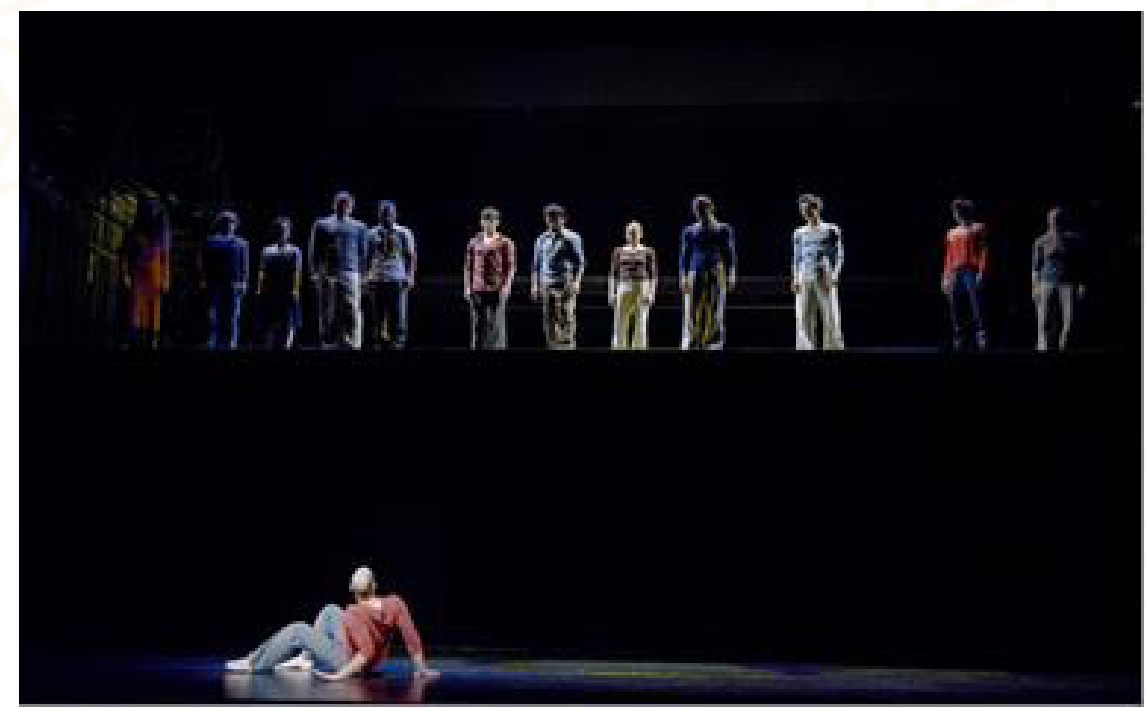

Figura 7 - Paul Hess e elenco Foto: Coleção Trier Theater. 
Lentamente a cena se desmembra a partir da movimentação do muro, que agora vai baixando e se transforma em uma espécie de escada muito larga, com degraus em diferentes níveis, onde todo o elenco realiza uma dança muito ritmada e sincopada, deslocando-se, descendo e subindo a escada. A cena é toda coreografada, apoiada no ritmo percussivo da música e, ao mesmo tempo, tem nuances de ações mais caóticas, em que os bailarinos vão trocando de lugar, para sempre voltar a repetir uma sequência em comum. A movimentação pode ser reconhecida como uma caligrafia típica de Susanne Linke. Caminhadas com pés e pernas em paralelo, relação forte com a terra, troca de peso das pernas e pés, junto com o quadril, que age como um motor que ativa e impulsiona os movimentos, que se sucedem com grande precisão. Parece-nos que cenas nas quais todo o elenco dança junto, com exatidão e força de um grande coro, são raras na contemporaneidade, mas quando acontecem, são muito envolventes.

Mareike Franz surge, então, mais uma vez com humor na cena, através de movimentos e ações regidas por palavras, mas, dessa feita, a bailarina usa um pequeno microfone, de maneira que é possível ouvir o que ela diz com precisão. O jogo de palavras e ações tem graça, exclamações, espanto, tem rimas, gestos, tem dança. $E$ tudo acontece com um ritmo muito festivo e inquietante.

O final da cena mostra os bailarinos retirando as fitas que prendem o linóleo preto no chão e, na sequência, eles começam a enrolar as faixas do linóleo nos respectivos rolos e retirá-los do palco. Como se realmente quisessem limpar a cena.

\section{Sobre chegadas}

Em NEMMOKNA, Susanne Linke utiliza o corpo como dramaturgia, a inspiração é o bailarino, sua personalidade e o que ele pode assimilar, transformar e transcender com o seu próprio corpo e suas movimentações. O lugar onde todas as ações acontecem é um palco italiano ${ }^{29}$, uma "caixa preta" aber-

29 Palco italiano: "Tipo de palco característico dos teatros europeus a partir do século XVII. Trata-se do palco retangular, aberto para a plateia na parte anterior e delimitado, à frente, pela boca de cena, e, ao fundo, pela rotunda ou ciclorama. A relação entre atores e espectadores é sempre frontal, determinada pelo ponto de vista estabelecido pela perspectiva. O palco italiano é, ainda, o mais comumente encontrado nos teatros existentes hoje em dia no mundo e, apesar das limitações que Ihe são atribuídas, oferece condições de visibilidade e acústica o mais próximos possível da perfeição" (VASCONCELLOS, 1997, p. 146). 
ta, sem cenário e vazio de adereços. Sua única variação são os planos, que se modificam através da maquinaria do teatro, e essas variações dos planos modificam fortemente o espaço cênico, dando à audiência a impressão de que todas as cenas acontecem em diferentes cenários. A trilha sonora é composta por uma colagem e composição musical de Wolfgang Bley-Borkowski, que tem colaborado com Linke em criações anteriores.

O epílogo da peça começa a ser preparado e a cena seguinte é precedida de um pequeno espaço de tempo e de um "vazio". É mostrado para a audiência o palco enorme, desnudado, sem nenhum adereço, que se alastra para as extremidades laterais e na sua profundidade.

A luz, muito clara, parece pretender que tudo seja muito bem visto. É então que a audiência ouve o ruído de uma nova estrutura térrea, que está sendo empurrada, mecanicamente, do fundo até a frente do palco. Assim que a estrutura está seguramente estabilizada, o bailarino polonês Robert Przybyl ${ }^{30}$, vestindo um figurino preto, entra em cena fazendo uma caminhada muito lenta e densa, parecendo que está vindo de muito longe. Quando o bailarino atinge um determinado lugar do palco, uma estrutura, de forma circular giratória, como uma espécie de carrossel térreo, começa a girar muito lentamente o chão, e Przybyl vai sendo conduzido por dentro da estrutura, sem parar de se movimentar. Nesse momento, aos pares, todo o elenco vai entrando em cena vagarosamente, vestidos com figurinos festivos e elegantes, na cor preta. Ao atingirem a estrutura circular giratória, todos iniciam uma espécie de valsa estilizada. Cada dupla, um rapaz e uma moça, dançam uma sequência própria. As sequências de cada dupla vão se transformando em caminhadas paralelas com deslocamentos do quadril, reconhecíveis como caminhadas

30 Robert Przybyl nasceu na Polônia. Depois de receber o seu diploma de Engenheiro Mestre na Universidade Técnica de Gdansk, estudou dança na Universidade Anton Bruckner. Durante o último ano de estudo, integrou a Companhia de Dança de Pós-graduação, pela qual dançou em peças de Avi Kaiser, Filip Van Huffel, Rose Breuss, Katherine Guerrin e Elio Gervasi. A seguir, foi para a Alemanha, onde dançou em Oldenburg, sob a direção de Martin Stiefermann e, depois, no Tanztheater Bremen, sob a direção de Urs Dietrich. Ao longo de sua carreira, dançou coreografias de Reinhild Hoffmann, Emanuel Gat, Tero Saarinen, Ingun Bjornsgaard, Rami Be'Er, Henrietta Horn, Tipo Weizmann, Roni Havers, entre outros. Desde 2001 cria as suas próprias obras - solos e duos, que tem apresentado em diferentes cidades europeias e na China, e também criou coreografias para companhias. Desde setembro de 2015, integra a Companhia Susanne Linke, no Trier Theater. 
com a assinatura de Susanne Linke, realizadas em um tempo lento, quase em slow motion, e dentro da estrutura circular, que segue girando lentamente.

Nos últimos instantes, uma chuva de papéis brilhantes cai do teto e, quando encontram o chão, o barulho corta a aura solene que a cena construiu e parece anunciar que, pelo menos naquele instante, o elenco de NEMMOKNA está chegando. Contudo, é uma chegada em movimento, alguns bailarinos seguem suas caminhadas em slow motion, e dois casais seguem dançando com suas valsas estilizadas ad infinitum.

São as palavras de Peter Brook (1998, p. 132) que nos encaminham para o final deste texto: "Terminar é o mais difícil de tudo, mas, mesmo assim, é a desistência que proporciona a única experiência verdadeira de liberdade. Então, o fim torna-se mais uma vez um começo, e a vida tem a última palavra".

O público presente na estreia de NEMMOKNA, no Teatro da cidade de Trier, não esperou muito tempo para reagir com um caloroso aplauso que durou muitos minutos. Um aplauso de gratidão por ter podido participar, de certa forma, daquele nascimento. A esperada entrada da coreógrafa Susanne Linke acaba sendo uma emoção à parte para o público presente. Mary Wigman, Dore Hoyer e Pina Bausch deixaram em Susanne Linke um "pensamento de movimento", que ela segue cultuando e ampliando, consequentemente. Linke é um arquivo vivo e complementa o passado com sua grande personalidade e estilo. A técnica que vem desenvolvendo e praticando de maneira aprofundada é atemporal e é estruturada na fisicalidade corporal. Por meio da técnica que desenvolveu, Linke não apenas aborda princípios da dança, mas guarda dentro dessa metodologia uma enorme herança que, para os bailarinos de seu ensemble, pode ser considerada algo fora do comum: dialogar com vivências que aconteceram no passado, transformando e recriando-as no presente, por meio de uma tradição corporal.

\section{Referências bibliográficas}

AGAMBEN, G. O que é o contemporâneo? e outros ensaios. Chapecó: Argos, 2009. BROOK, P. Fios do tempo: memórias. Rio de Janeiro: Bertrand Brasil, 1998.

KÔKÔ, K. Der Körper ist eine Bibliotek. In: ODENTHAL, J. Tanz Körper Politik. Berlin: Theater der Zeit, 2005. 
MARKARD, A.; MARKARD, H. Jooss. Köln: Ballett - Bühneverlag Rolf Garske, 1985. PEREIRA, S. Rastros do Tanztheater no processo criativo de ES-BOÇO: espetáculo cênico com alunos do Instituto de Artes da Unicamp. 2007. Tese (Doutorado em Artes) - Instituto de Artes. Unicamp, Campinas, 2007.

Susanne Linke mantém vivo o legado do Tanztheater alemão. Disponível em: <http://www.conectedance.com.br/ponto-de-vista/susanne-linke-mantem-vivo-o-legado-do-tanztheater-alemao/>. Acesso em: 3 mar. 2016.

SCHECHNER, R. Performer. Sala Preta, São Paulo, v. 9, p. 333-365, 2009. Disponível em:

<http://www.revistas.usp.br/salapreta/article/view/57416/60398>. Acesso em: 10 mar. 2016.

VASCONCELLOS, L. P. Dicionário de teatro. São Paulo: L\&PM, 1997.

Recebido em 26/04/2016

Aprovado em 17/05/2016

Publicado em 01/07/2016 